\title{
MONITORAMENTO DA QUALIDADE DA ÁGUA NAS BACIAS DO PARANAPANEMA III E IV: PARÂMETROS FÍSICOS
}

Osvaldo Tarelho Junior ${ }^{11}$

Cássia Maria Bonifácio²

Célia Regina Granhen Tavares ${ }^{3}$

RESUMO: As bacias do rio Paranapanema III e IV são de grande importância no que tange à captação de águas para abastecimento, ao desenvolvimento de atividades agropecuárias e ao turismo nos municípios que nelas se inserem. Estas bacias possuem ocupação mista, urbana e rural. Devido aos diferentes tipos de uso e manejo, sofrem com o contínuo crescimento urbano, e também com a modificação da cobertura do solo para as atividades agrícolas. Em eventos de precipitação, as alterações causadas pelo uso e ocupação do solo, podem ser refletidas na qualidade do corpo d'água. Sendo assim, realizou-se monitoramento de parâmetros físicos de qualidade da água (sólidos totais, temperatura, cor, turbidez e condutividade elétrica), entre os meses de fevereiro a julho de 2013, a partir da coleta e análises in loco e em bancada, seguindo metodologias já consolidadas. Os dados obtidos foram agrupados por parâmetros e comparados aos limites superiores estabelecidos pela Resolução CONAMA 357, de 2005, e suas alterações. Foi registrada apenas uma não conformidade à resolução de referência, no parâmetro cor, e observou-se que há relação de causa e efeito entre o uso e ocupação do solo nas bacias e a qualidade dos corpos hídricos estudados.

Palavras-chave: Qualidade da água. Parâmetros físicos. Bacias do Paranapanema III e IV.

\footnotetext{
${ }^{1}$ Engenheiro Químico, Mestrando em Engenharia Química, Bolsista CAPES. Universidade Estadual de Maringá. Email: osvaldotarelhojr@hotmail.com

${ }^{2}$ Geógrafa, Mestre em Geografia, Pesquisadora Bolsista CNPQ/FINEP. Universidade Estadual de Maringá. Email: kaoruyuri@hotmail.com

${ }^{3}$ Prof. ${ }^{\text {a }}$ Dr. ${ }^{\text {a }}$ do Departamento de Engenharia Química. Universidade Estadual de Maringá. celiagranhen@gmail.com
} 


\section{INTRODUÇÃO}

A água é um recurso natural de disponibilidade relativamente alta se comparada a outras fontes e de maior acessibilidade a seus usuários, encontrando-se alojada em reservas subterrâneas e superficiais, bem como em forma de vapor na atmosfera. Possui importância econômica, uma vez que é fator limitante em inúmeras atividades nas quais é empregada como insumo, seja no meio urbano, em sua distribuição e uso em processos industriais, seja em áreas agrícolas, em que é utilizada para irrigação.

A qualidade dos recursos hídricos pode ser entendida como um reflexo direto das atividades desenvolvidas em determinada região, bem como do uso e ocupação do solo nas mediações dos cursos d'água, que irão receber, por meio de drenagem e do escoamento superficial, a carga de matéria e de sedimentos proveniente de seu entorno. Comumente, para fins de estudo de um curso d'água em termos de parâmetros de qualidade e dos impactos a eles associados, elege-se como unidade de gerenciamento a bacia hidrográfica na qual tal manancial está contido.

Como bacia hidrográfica entende-se:

[...] área de captação natural da água de precipitação que faz convergir o escoamento para um único ponto de saída. A bacia hidrográfica compõese de um conjunto de superfícies vertentes e de uma rede de drenagem formada por cursos de água que confluem até resultar em um leito único no seu exutório. (TUCCI, 1997)

Freitas (2000) elenca o monitoramento ambiental como um dos instrumentos da gestão de bacias hidrográficas e cita que a maioria dos problemas de causa-efeito gerados correlaciona-se ao uso dos recursos hídricos, cuja rede de drenagem conforma a estes problemas.

Particularmente, o monitoramento da qualidade da água via parâmetros físicos, como temperatura, condutividade térmica, presença de sólidos, turbidez e cor, num intervalo temporal, fornecerá dados a respeito das características das atividades predominantes naquela bacia e do tipo de solo presente e sua maior ou menor exposição em determinados período, o que contribui ao maior ou menor carreamento superficial de sedimentos até a calha do curso d'água principal. 
Diante do exposto, o presente trabalho tem por objetivo monitorar parâmetros físicos da qualidade de corpos hídricos contribuintes do Rio Paranapanema, os quais se localizam em duas bacias hidrográficas do Estado do Paraná: Bacia do Paranapanema III e IV. Serão abordados os seguintes aspectos:

- Análise e monitoramento da qualidade da água in natura de cursos d'água em relação aos parâmetros físicos: temperatura (da água e do ar), cor, turbidez, sólidos (filtráveis e totais) e condutividade elétrica;

- Avaliar a conformidade dos dados com a Resolução CONAMA 375-2005 e suas alterações;

- Verificar a influência do uso e da ocupação do solo na qualidade da água nas bacias estudadas.

\section{DESENVOLVIMENTO}

O desenvolvimento deste trabalho é subdividido em três etapas: caracterização das áreas de estudo, metodologia e resultados e discussão.

\subsection{Caracterização das áreas de estudo}

\subsubsection{Bacia do Paranapanema III}

A Bacia do Paranapanema III é formada pela área de drenagem de 12 tributários que deságuam no rio Paranapanema entre a foz do rio Tibagi, próximo ao lago da Usina Hidrelétrica de Capivara, e a foz do rio Pirapó - PR. Possui uma área total de 3.564,30 km2, cerca de 2\% da área do Estado, compreendendo 19 municípios e uma população de 110.516 habitantes, sendo 84.583 na zona urbana (IBGE - 2004). O índice de atendimento para abastecimento público de água supera $99 \%$ e o de coleta de efluentes domésticos fica em torno de $29 \%$.

Em relação ao uso do solo, a bacia é ocupada em grande parte com a classe de agricultura intensiva, com áreas de pastagens artificiais e campos naturais nos extremos leste e oeste, $\mathrm{Na}$ região central há uma grande área de uso misto, com pequenas 
aparições de cobertura florestal, embora não apresente áreas de Unidades de Conservação e Corredores de Biodiversidade. Em usos rurais, a bacia apresenta vulnerabilidade à contaminação do aquífero Caiuá e, em usos urbanos, há baixa infraestrutura de esgotos e drenagem.

A demanda hídrica da bacia é de aproximadamente $1,2 \mathrm{mil} \mathrm{L} / \mathrm{s}$, dos quais $81 \%$ provêm de mananciais superficiais e 19\% de mananciais subterrâneos, Com relação ao uso dos recursos hídricos, $17 \%$ vão para o abastecimento público, 31\% para o uso industrial, $41 \%$ para o setor agrícola, $11 \%$ para o setor pecuário e o setor mineral com menos de 1\%. A disponibilidade hídrica superficial é de $16 \mathrm{mil} \mathrm{L} / \mathrm{s}$ e o valor demandado é de $1 \mathrm{mil} \mathrm{L/s}$, ao passo que a disponibilidade hídrica subterrânea é estimada em $4 \mathrm{mil} \mathrm{L} / \mathrm{s}$, provida pelos aquíferos Guarani, Serra Geral Norte e Caiuá. (SEMA, 2010).

\subsubsection{Bacia do Paranapanema IV}

A Bacia do Paranapanema IV localiza-se a oeste do rio Pirapó, contando com 15 afluentes do rio Paranapanema até a foz do Ribeirão do Tigre. Possui uma área total de $4.139 \mathrm{~km} 2$ (2\% da área do Estado), abrangendo 18 municípios e uma população total de 80.808 habitantes, sendo 58.692 vivendo na zona urbana (IBGE - 2004). O abastecimento público de água atende $98 \%$ dos habitantes e a coleta de esgotos atinge um índice de $14 \%$. Sobre o uso do solo, a bacia é quase que integralmente ocupada por pastagem artificial e campos naturais, ocorrendo pequenas áreas de agricultura intensiva (cana-deaçúcar) e cobertura vegetal.

A bacia apresenta grande área de Corredores de Biodiversidade, que vão desde a região central até o extremo oeste, além de pequena faixa de Unidades de Conversação na porção noroeste. Em usos rurais, há risco de contaminação do aquífero Caiuá e, em usos urbanos, baixa infraestrutura de esgotos e drenagem e grande volume de resíduos domiciliares destinados a lixões. A bacia possui uma demanda hídrica estimada em 0,5 mil L/s, dos quais $47 \%$ provêm de mananciais superficiais e $53 \%$ de mananciais subterrâneos. Em relação à utilização dos recursos hídricos, 25\% são direcionados ao abastecimento público, 18\% para atividade industrial, $7 \%$ ao setor agrícola, $50 \%$ para a pecuária e menos de $1 \%$ para o setor mineral. A disponibilidade hídrica superficial é de 20 


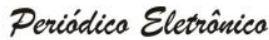

mil L/s e o valor demandado é de 0,2 mil L/s. Já a disponibilidade hídrica subterrânea é estimada em 3 mil L/s, a partir dos aquíferos Guarani e Caiuá. (SEMA, 2010)

\subsection{Metodologia}

Para melhor entendimento, esta parte do trabalho foi segmentada nos seguintes tópicos: definição dos pontos de coleta; campanhas mensais de coleta de amostras; análise in loco e análise em bancada dos parâmetros de qualidade.

\subsubsection{Definição dos pontos de coleta}

Os pontos de coleta foram definidos a partir das características geomorfológicas de cada região, no que se refere a tipo de solo, relevo, atividades predominantes no entorno (agropecuária, culturas temporárias ou permanentes). Optou-se por locais em que o acesso fosse favorável e onde houvesse ponte sobre o curso d'água. Foram definidos três pontos de coleta em cada bacia, os quais são descritos no Quadro 1 e podem ser visualizados nas Figuras 1(a) e 1(b).

\begin{tabular}{|c|c|c|c|}
\hline PONTO & Bacia & Curso d'água & Município \\
\hline 1 & \multirow{3}{*}{ Paranapanema III } & Ribeirão Vermelho & Cambé \\
\hline 2 & & Ribeirão Vermelho & $\begin{array}{c}\text { Divisa entre } \\
\text { Florestópolis e Alvorada } \\
\text { do Sul }\end{array}$ \\
\hline 3 & & Ribeirão Caneleiro & Centenário do Sul \\
\hline 4 & \multirow{3}{*}{ Paranapanema IV } & Ribeirão Francisco & $\begin{array}{l}\text { Divisa entre Cruzeiro do } \\
\text { Sul e Alto Paraná }\end{array}$ \\
\hline 5 & & Ribeirão Francisco & $\begin{array}{l}\text { Divisa entre São João } \\
\text { do Caiuá e Paranacity }\end{array}$ \\
\hline 6 & & Rio da Coroa do Frade & $\begin{array}{c}\text { Divisa entre Terra Rica } \\
\text { e Paranavaí }\end{array}$ \\
\hline
\end{tabular}

Quadro 1 - Descrição dos pontos de coleta. Fonte: Elaborado pelo autor

Figuras 1(a) e 1(b) - Indicação dos pontos de coleta das Bacias do Paranapanema III e IV ${ }^{2}$

\footnotetext{
${ }^{2}$ Os mapas das bacias hidrográficas foram obtidos originalmente a partir de banco de dados geográficos do PGE-UEM (Programa de Pós-Graduação em Geografia), sem possuir quaisquer indicações dos pontos de coleta (triângulos em cor preta) ou descrição por extenso. A inclusão de tais marcações foi feita em primeiro plano, posteriormente, pelo autor.
} 
Fig. 1(a)

Fig. 1(b)
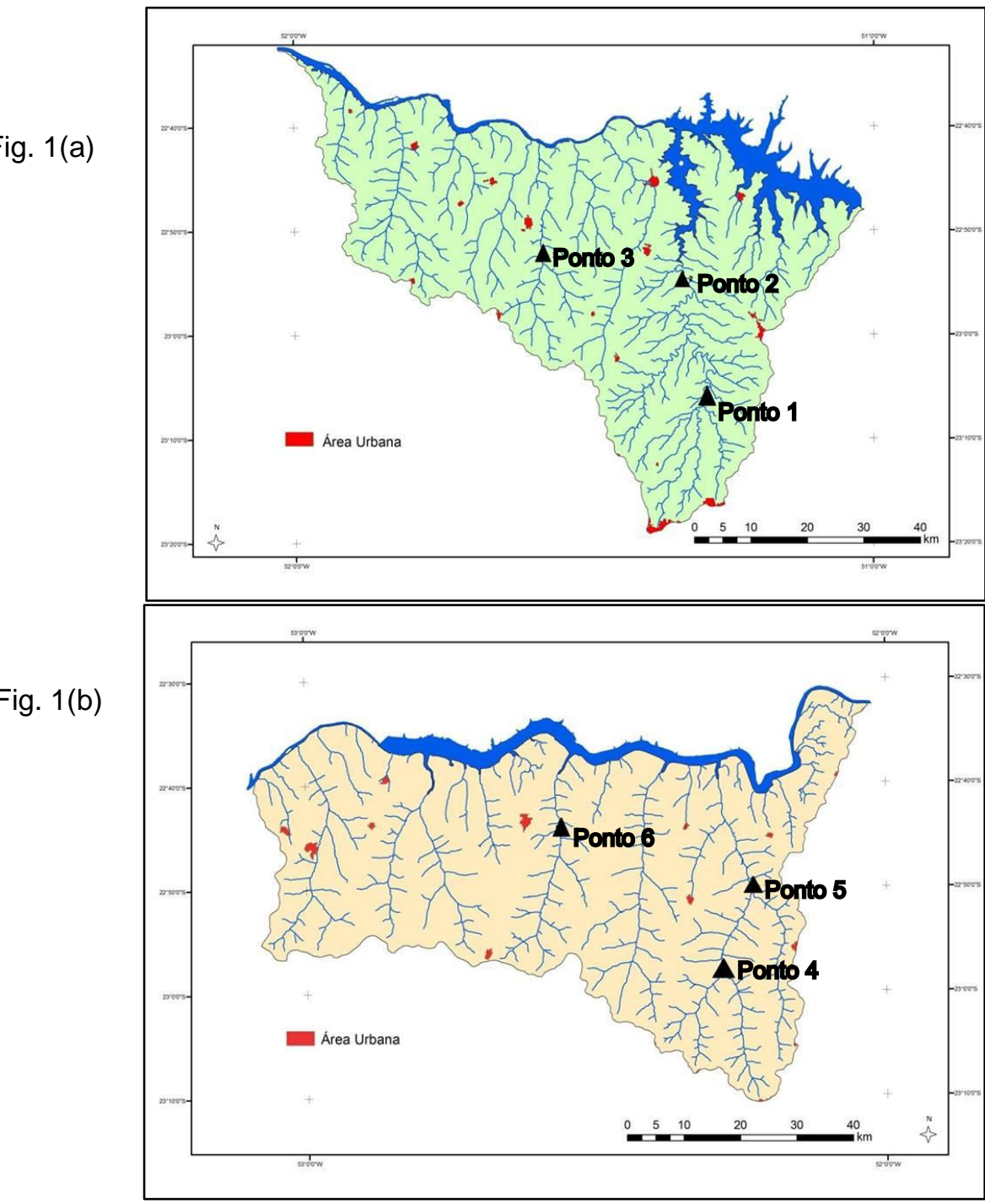

Fonte: PGE-UEM, adaptado pelo autor

2.2.2 Campanhas mensais de coleta de amostras

As campanhas de coleta de amostras têm periodicidade mensal, o deslocamento até os pontos é feito por veículo modelo L-200 em cuja carroceria são transportadas caixas térmicas com capacidade para acondicionar frascos de plástico opacos de volumes diversos, no interior dos quais as amostras são preservadas inicialmente com gelo e, posteriormente, estocadas em freezer. Para a análise dos parâmetros cor, turbidez e sólidos (suspensos e totais), utiliza-se amostras estocadas em frascos de $2000 \mathrm{~mL}$ e os demais frascos contém amostras para a determinação de parâmetros não incluídos no escopo deste trabalho. 


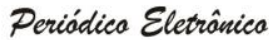

Ao acessar cada ponto, inicia-se o procedimento de coleta: lança-se um balde sustentado por corda ponte abaixo em posição que coincida com o ponto médio transversal do leito do curso d'água, em que há a melhor mistura do fluido, e, preenchido o recipiente, iça-se o mesmo manualmente. Parte da água coletada é homogeneizada e inserida nos frascos para preservação das amostras e parte é mantida no balde para se proceder à medida in loco de parâmetros e depois descartada.

Não foram realizadas coletas no mês de fevereiro para os pontos da Bacia do Paranapanema III e do ponto 6 da Bacia do Paranapanema IV, pois estes ainda não haviam sido definidos.

\subsubsection{Análise in loco}

Os parâmetros medidos in loco são a temperatura do ar, a temperatura da água e a condutividade elétrica. $O$ primeiro parâmetro é determinado via termômetro com graduação de 0 a $70^{\circ} \mathrm{C}$ e os demais são determinados com o auxílio de sonda marca Hach, a qual dispõe de eletrodos cujas extremidades são mergulhadas no interior do recipiente coletor e que, após a medida concluída, são limpos com água deionizada. As temperaturas do ar e da água são medidas em graus Celsius $\left({ }^{\circ} \mathrm{C}\right)$ e a condutividade elétrica é medida em microsiemens por centímetro $\left(\mu \mathrm{S} . \mathrm{cm}^{-1}\right)$.

\subsubsection{Análise em bancada}

Em bancada (laboratório), procederam-se as análises dos parâmetros: cor, turbidez e sólidos (suspensos e totais). Para a análise da variável cor, determinada em unidades de platina-cobalto, utiliza-se metodologia descrita pelo equipamento Portable Datalogging Spectrophotometer $\mathrm{HACH}$ DR/2010. A turbidez era determinada via turbidímetro da Polilab, modelo AP1000II, o qual fornece a leitura em unidade nefelométrica de turbidez (NTU). A concentração de sólidos em cada amostra era determinada por meio de análise gravimétrica conforme procedimento experimental descrito em Standard Methods for the Examination of Water and Wastewater (APHA, 1998). 


\subsection{Resultados e Discussão}

Os parâmetros analisados foram dispostos em tabelas cujas colunas representam a ordem dos pontos e as linhas indicam o mês de coleta das amostras.

\subsubsection{Temperatura da água vs. Temperatura do ar}

A Tabela 1 apresenta os dados de medição da temperatura da água e a Tabela 2 traz os dados das medidas de temperatura do ar no momento da coleta.

Tabela 1 - Medidas de Temperatura da água $\left({ }^{\circ} \mathrm{C}\right)$ nos pontos de coleta entre fev-jul 2013

\begin{tabular}{ccccccc} 
& \multicolumn{3}{c}{ PARANAPANEMA 3 } & \multicolumn{3}{c}{ PARANAPANEMA 4 } \\
CAMPANHAS & PONTO & PONTO & PONTO & PONTO & PONTO & PONTO \\
& 1 & 2 & 3 & 4 & 5 & 6 \\
fev/13 & & & & 25,5 & 24,6 & \\
mar/13 & 26,3 & 28,1 & 27,6 & 26,7 & 27,5 & 29,7 \\
abr/13 & 22,3 & 24 & 25,1 & 22,6 & 24,8 & 31,9 \\
mai $/ 13$ & 19 & 17,5 & 17,4 & 17,2 & 19,1 & 19,7 \\
jun $/ 13$ & 20,9 & 20,5 & 20,3 & 22,5 & 24,1 & 24,3 \\
jul/13 & 21,4 & 22,3 & 22,7 & 23,7 & 22,8 & 24,8 \\
\hline
\end{tabular}

Fonte: Elaborada pelo autor

Tabela 2 - Medidas de Temperatura do ar $\left({ }^{\circ} \mathrm{C}\right)$ nos pontos de coleta entre fev-jul 2013

\begin{tabular}{ccccccc} 
& \multicolumn{3}{c}{ PARANAPANEMA 3 } & \multicolumn{4}{c}{ PARANAPANEMA 4 } \\
CAMPANHAS & PONTO & PONTO & PONTO & PONTO & PONTO & PONTO \\
fev/13 & 1 & 2 & 3 & 4 & 5 & 6 \\
mar/13 & 34 & 36 & 33 & 32 & 24 & \\
abr/13 & 24,1 & 27,2 & 30 & 28,5 & 32 & 36 \\
mai $/ 13$ & 22 & 20 & 21,5 & 18 & 21 & 25 \\
jun $/ 13$ & 21 & 22 & 24 & 27 & 27 & 28 \\
jul/13 & 26 & 26 & 28 & 31 & 30 & 27 \\
\hline
\end{tabular}

Fonte: Elaborada pelo autor

Observa-se a partir dos dados das Tabelas 1 e 2 que, em termos gerais, a temperatura da água é inferior à do ar, uma vez que há a transferência de calor entre os meios ar-água e no interior do corpo hídrico por convecção, fazendo com que no decorrer do tempo as temperaturas tendam ao equilíbrio, o que não significa necessariamente que se igualem. Em dias com temperaturas menores, como as medidas em maio de 2013, 
nota-se que a diferença de temperatura entre os meios se atenua se comparada à mesma diferença em dias com temperaturas um pouco mais elevadas.

\subsubsection{Condutividade térmica}

A Tabela 3 apresenta os dados obtidos a partir das medidas de condutividade elétrica em cada ponto de coleta ao longo dos meses.

Tabela 3 - Medidas de condutividade elétrica $\left(\mu \mathrm{S} . \mathrm{cm}^{-1}\right)$ nos pontos de coleta entre fev-jul 2013

\begin{tabular}{ccccccc} 
& \multicolumn{3}{c}{ PARANAPANEMA 3 } & \multicolumn{3}{c}{ PARANAPANEMA 4 } \\
CAMPANHAS & PONTO & PONTO & PONTO & PONTO & PONTO & PONTO \\
fev/13 & 1 & 2 & 3 & 4 & 5 & 6 \\
mar/13 & 101,9 & 102,2 & 41,7 & 57,8 & 55,2 & \\
abr/13 & 92,2 & 95,8 & 41,5 & 57,9 & 53,5 & 35,1 \\
mai/13 & 83,6 & 93,9 & 41,2 & 50,9 & 49,7 & 33,2 \\
jun $/ 13$ & 90 & 97,6 & 42,3 & 56,9 & 53,1 & 36,6 \\
jul/13 & 84,5 & 89,4 & 40,3 & 54,4 & 49,8 & 35,7 \\
\hline
\end{tabular}

Fonte: Elaborado pelo autor

As medidas de condutividade elétrica refletem a maior ou menor quantidade de íons presentes na solução aquosa, podem guardar relação com o tipo de solo predominante no entorno de cada ponto de coleta e com as atividades (agrícolas ou industriais) ali desenvolvidas.

Observam-se os valores máximos de condutividade elétrica nos pontos 1 e 2, localizados no mesmo curso d'água, com uma tendência de pequena diminuição ao longo dos meses. Os pontos 4 e 5 também foram locados num mesmo corpo hídrico, apresentando valores muito próximos do parâmetro em questão. Ressalta-se que existe atividade agrícola no entorno dos pontos supracitados, mais especificamente a cultura permanente de cana-de-açúcar e rotação de culturas temporárias como soja, milho e trigo.

Os menores valores de condutividade elétrica foram medidos nos pontos 3 e 6 , sendo o mínimo neste último ponto. A paisagem predominante no entorno do trecho representado por tais pontos é de pastagens e pequenos trechos de área de preservação, diferindo das observadas nos trechos representados pelos pontos em que se verificaram 
valores maiores do mesmo parâmetro. É razoável, portanto, associar os dados de condutividade elétrica com o uso e a ocupação do solo nas regiões de estudo.

\subsubsection{Turbidez}

Os dados relativos às medidas de turbidez (NTU) são apresentados na Tabela 4.

Tabela 4 - Medidas de turbidez (NTU) nos pontos de coleta entre fev-jul 2013

\begin{tabular}{ccccccc} 
& \multicolumn{3}{c}{ PARANAPANEMA 3 } & \multicolumn{4}{c}{ PARANAPANEMA 4 } \\
CAMPANHAS & PONTO & PONTO & PONTO & PONTO & PONTO & PONTO \\
& 1 & 2 & 3 & 4 & 5 & 6 \\
fev/13 & & & & 46,5 & 64,0 & \\
mar/13 & 45,0 & 73,0 & 22,0 & 35,7 & 54,9 & 44,8 \\
abr/13 & 40,7 & 57,1 & 21,2 & 33,7 & 47,0 & 92,4 \\
mai $/ 13$ & 37,4 & 47,8 & 14,7 & 35,1 & 61,9 & 37,4 \\
jun $/ 13$ & 59,2 & 78,2 & 30,1 & 51,8 & 54,4 & 22,6 \\
jul/13 & 48,4 & 45,7 & 21,9 & 36,7 & 37,6 & 72,6 \\
\hline
\end{tabular}

Fonte: Elaborada pelo autor

A avaliação da turbidez reflete a presença de sólidos em suspensão em cada amostra. A partir dos dados apresentados na Tabela 4, observa-se que, ao longo do período de medições, o ponto 3 apresentou os valores mínimos deste parâmetro e, de fato, percebeu-se visualmente uma maior limpidez do curso d'água em comparação com os demais. O valor máximo, 92,4 NTU, foi medido na campanha do mês de abril de 2013, no ponto 6, no entanto não excedeu o limite superior estabelecido pela Resolução CONAMA 357, de 2005, cujo valor é de até 100 NTU para águas doces Classes 2 e 3.

Os valores de turbidez podem ser reflexo da maior ou menor exposição do solo no entorno dos pontos, que seria fator contribuinte para o carreamento de sedimentos via escoamento superficial até o leito do rio. A fragilidade do solo e a cessão das encostas também podem favorecer os valores maiores de turbidez, além de períodos de precipitação elevada.

\subsubsection{Cor verdadeira}

A Tabela 5 apresenta os dados referentes às medidas de cor, em mgPt-Co. $\mathrm{L}^{-1}$, ao longo do período de estudo, para cada um dos pontos de coleta. 
Tabela 5 - Avaliação do parâmetro cor $\left(\mathrm{mgPt}-\mathrm{Co}_{\mathrm{L}} \mathrm{L}^{-1}\right)$ nos pontos de coleta entre fev-jul 2013

\begin{tabular}{ccccccc} 
& \multicolumn{3}{c}{ PARANAPANEMA 3 } & \multicolumn{3}{c}{ PARANAPANEMA 4 } \\
CAMPANHAS & PONTO & PONTO & PONTO & PONTO & PONTO & PONTO \\
& 1 & 2 & 3 & 4 & 5 & 6 \\
fev/13 & & & & 46,0 & 59,3 & \\
mar/13 & 44,0 & 75,0 & 58,0 & 30,0 & 31,0 & 26,0 \\
abr/13 & 39,0 & 60,0 & 36,0 & 40,0 & 57,0 & 35,0 \\
mai/13 & 16,0 & 27,0 & 0,0 & 4,0 & 40,0 & 39,0 \\
jun/13 & 23,0 & 41,0 & 53,0 & 44,0 & 46,0 & 90,0 \\
jul/13 & 10,0 & 15,5 & 5,5 & 2,0 & 7,5 & 8,0 \\
\hline
\end{tabular}

Fonte: Elaborada pelo autor

O parâmetro cor está associado à presença de substâncias orgânicas ou inorgânicas que possuem a característica de reduzir a intensidade da luz quando esta penetra na amostra. Os dados da Tabela 5 mostram que, no período de fevereiro a julho de 2013, houve algumas variações bruscas nos valores do parâmetro em certos pontos de coleta e que, até então, não se nota uma tendência de diminuição ou aumento em quaisquer combinações, bacias ou pontos.

O valor máximo encontrado foi de $90,0 \mathrm{mgPt}-\mathrm{Co}_{\mathrm{L}} \mathrm{L}^{-1}$, no ponto 6 , na campanha do mês de junho de 2013. Este valor representa uma não conformidade à Resolução 357, de 2005, tendo em vista que o limite superior do parâmetro cor em águas doces, Classes $2 \mathrm{e}$ 3 , não deve exceder $75 \mathrm{mgPt}-\mathrm{Co}_{\mathrm{L}} \mathrm{L}^{-1}$. Os demais pontos atendem a esta legislação por possuírem valores menores ou iguais ao mencionado.

\subsubsection{Sólidos totais}

Os dados relativos às medidas do parâmetro sólidos totais, em mg. $\mathrm{L}^{-1}$, ao longo do período de estudo, são apresentados no Gráfico 1. 


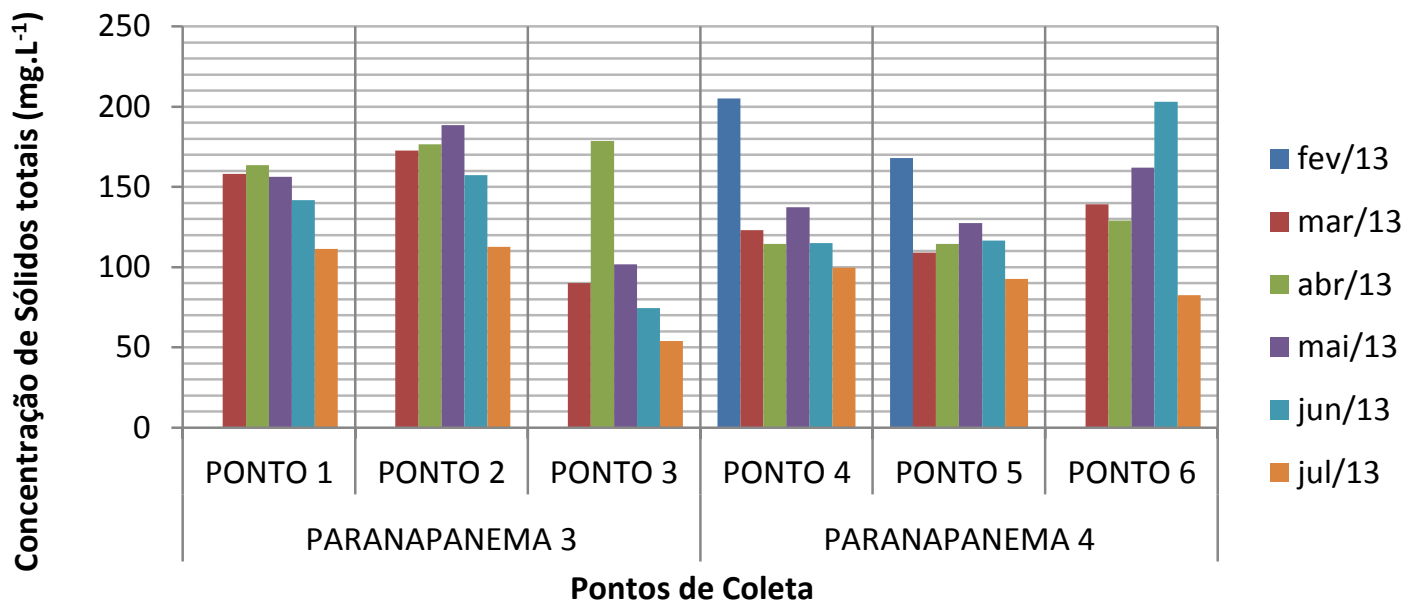

Gráfico 1 - Concentração de sólidos totais, em mg. $\mathrm{L}^{-1}$, nos pontos de coleta entre fev-jul 2013 Fonte: Elaborado pelo autor

Os valores medidos para o parâmetro sólidos totais, assim como para o parâmetro turbidez, estão associados à presença de sedimentos em suspensão no corpo hídrico, provenientes de arraste superficial, em períodos de maior precipitação, além da exposição e fragilidade do solo. No período de estudo, não foram registradas não conformidades à Resolução CONAMA 357, de 2005, que fixa como limite superior a concentração de 500 $\mathrm{mg} . \mathrm{L}^{-1}$ para sólidos dissolvidos totais. Acompanhando o comportamento descrito no item 2.3.3, entre os meses de março e julho, o ponto 3 apresentou as menores concentrações de sólidos totais quando comparadas com as dos demais pontos.

\section{CONCLUSÕES}

A partir da análise dos resultados é possível concluir que o monitoramento da qualidade da água a partir dos parâmetros físicos apresentou resultados que estão diretamente relacionados com o uso e a ocupação do solo no entorno de cada ponto de coleta. Observou-se também que, tendo como referência legal a Resolução CONAMA 357, de 2005, existe não conformidade pontual do parâmetro cor, para o ponto de coleta 6 (seis). O mesmo curso d'água se mostrou destoante no parâmetro condutividade elétrica, resultando valores mínimos de medida. O ponto de coleta 3 (três) apresentou valores 
mínimos para os parâmetros turbidez e sólidos totais. Nos demais parâmetros, não se verificou tendência de máximos e mínimos em relação aos pontos de coleta.

\section{AGRADECIMENTOS}

Os autores agradecem ao CNPq, à CAPES e à FINEP pelo auxílio financeiro.

\section{REFERÊNCIAS}

APHA. American Public Health Association. Standard Methods for the Examination of Water and Wastewater. Washington, D.C, 1998.

BRASIL. Conselho Nacional do Meio Ambiente. Resolução ํㅜ 357, de 17 de Março de 2005. Dispõe sobre a classificação dos corpos de água e diretrizes ambientais para o seu enquadramento, bem como estabelece as condições e padrões de lançamento de efluentes, e dá outras providências. Diário Oficial [da] República Federativa do Brasil. Brasília, DF, 18 mar. 2005.

Resolução no 430, de 13 de Maio de 2011. Dispõe sobre as condições e padrões de lançamento de efluentes, complementa e altera a Resolução oㅜ 357, de 17 de março de 2005, do Conselho Nacional do Meio Ambiente-CONAMA. Diário Oficial [da] República Federativa do Brasil. Brasília, DF, 16 maio 2011.

FREIRE, R. Monitoramento da qualidade da água da bacia hidrográfica do ribeirão Maringá. 2010. Dissertação (Mestrado em Engenharia Química) - Departamento de Engenharia Química, Universidade Estadual de Maringá, Maringá, 2010.

FREITAS, A. J. Gestão de Recursos Hídricos. In: SILVA, D. D.; PRUSKI, F. F. (Editores). Gestão de recursos hídricos: aspectos legais, econômicos, administrativos e sociais. Brasília: Ministério do Meio Ambiente, Secretaria de Recursos Hídricos; Viçosa: Universidade Federal de Viçosa; Porto Alegre: Associação Brasileira de Recursos Hídricos, 2000.

OLIVEIRA, T. M. Diagnóstico da qualidade físico-química e biológica da bacia do alto rio Pirapó. 2004. -Dissertação (Mestrado em Engenharia Química) - Departamento de Engenharia Química, Universidade Estadual de Maringá, Maringá, 2004. 
PERUÇO, J. D. Identificação das principais fontes poluidoras de afluentes da bacia do alto rio Pirapó. 2004. - Dissertação (Mestrado em Engenharia Química) Departamento de Engenharia Química, Universidade Estadual de Maringá, Maringá, 2004.

SECRETARIA DE ESTADO DO MEIO AMBIENTE E RECURSOS HÍDRICOS. Bacias hidrográficas do Paraná: série histórica. Curitiba: SEMA, 2010. SGORLON, J. G. Monitoramento da qualidade da água da bacia do médio rio Pirapó. 2011.

Dissertação (Mestrado em Engenharia Química) - Departamento de Engenharia Química, Universidade Estadual de Maringá, Maringá, 2011.

TUCCI, C. E. M. 1997. Hidrologia: ciência e aplicação. 2. ed. Porto alegre: ABRH/ Editora da UFRGS, 1997. (Col. ABRH de Recursos Hídricos, v.4).

VON SPERLING, M.. Princípios do tratamento biológico de águas residuárias. Vol. 1. Introdução à qualidade das águas e ao tratamento de esgotos. Departamento de Engenharia Sanitária e Ambiental - UFMG. 2ª ed. Belo Horizonte, 1996.

Princípios do tratamento biológico de águas residuárias. Vol. 7. Estudos e modelagem da qualidade da água de rios. Departamento de Engenharia Sanitária e Ambiental - UFMG. Belo Horizonte, 2008. 